\author{
University of Newcastle, Swinburne University of Technology, Griffith \\ University
}

Susan Kerrigan, Pieter Aquilia, Jill Holt and Nicholas Oughton

\title{
Australian universities approaches to Occupational Risk Management for screen production
}

\begin{abstract}
$\underline{\text { Abstract }}$
Australian screen production programs, offering both undergraduate and post-graduate degrees, continue to face challenges in upholding professional levels of Occupational Risk Management (ORM) within a student environment. These programs must address the confines of rigid ORM criteria within their university, which are largely designed for science-based academic research, and also adhere to standards of industrial health and safety codes set by state and federal governments. To date, academic literature in the area has been minimal, and many screen production programs have looked to industry and professional bodies for student guidelines. However, Oughton (2010) argues that even the existing ORM model for the creative arts requires revision. In an attempt to understand the current profile of ORM education and practices within screen production programs, the Australian Screen Production Education and Research Association (ASPERA) conducted a study amongst its 20 member institutions. A survey was administered and a case study was sought from one of the leading academic institutions in screen production in Australia. The goal of the study is a preliminary recommendation, which suggests a plan for a ORM Best Practice Model that will address the management of ORM issues across a range of screen production education programs on offer within Australia.
\end{abstract}

\section{Biographical notes:}

Susan Kerrigan is the Program Convenor for the Bachelor of Communication at the University of Newcastle, NSW, Australia. Susan's teaching and research is informed by her past professional practice, as a TV Producer/Director for the Australian Broadcasting Corporation, where she worked on the iconic children's program 'Play School'. She completed her $\mathrm{PhD}$ in 2010 on the topic of Creative Documentary Practice and has presented her research at international conferences and has published internationally in the field of Creative Screen Practice. Susan is an executive member of the Australian Screen Production, Education and Research Association (ASPERA).

Dr. Pieter (Pia) Aquilia has lectured film and television since 1988 at universities in Australia and Singapore. She is currently Associate Professor at the University of Newcastle and adjunct faculty at NYU's Tisch Asia in Singapore. She is a graduate in 
film scriptwriting and direction from the Australian Film, Television and Radio School; she has an extensive background as a scriptwriter, script editor and director in film and television drama. She is a regular consultant for broadcasters in Southeast Asia and the author of books, chapters and journal articles on film, television and new media in Australasia.

Jill Holt started her career as a film editor, and has worked extensively in all areas of the industry including feature films, short films, documentary and television commercials. Jill completed a Master of Design in Multimedia Design at Swinburne University in 2005, and since that time has held the position of Program Coordinator of the Swinburne School of Film and Television in Melbourne. She lectures in postproduction and editing, and has recently commenced a $\mathrm{PhD}$ on the topic of creative editing practice within Australia. She is also an active member of various industry \& educational organizations including the Australian Screen Editors Guild (ASE), and the Australian Screen Production Education And Research Association (ASPERA).

Nicholas Oughton has worked as a director, producer and production manager on a wide range of productions, which include television commercials, documentary, educational and short feature films. Nicholas's research encompasses many aspects of Risk Management and OHS relating to the arts, creative practice, and the film and television industries. This research has been published in national and international refereed journals. He has also been involved in education since 1980 holding senior leadership positions such as Associate Director, TAFE and Head, Griffith Film School. He has written and supervised the delivery of many graduate and post-graduate degree programs. He is currently the Convener of Film and Television Production at Griffith University, is an executive officer and Past President of the Australian Screen Production, Education and Research Association (ASPERA). Nicholas also serves on the jury of a number of International Film Festivals

\section{Keywords:}

OHS - Risk management - Screen production - Filmmaking 


\section{Introduction}

Most universities in Australia offer some type of screen production program. This ranges from professional training courses such as Australian Film, Television and Radio School, (AFTRS) to universities such as University of Newcastle (UoN), which offer a third of its degree as a Media Production major. The screen education environment in Australia has changed dramatically since the late 1970s and early 1980's when film and video production courses proliferated as an alternative to industry training. The adoption of new media technologies in recent years has resulted in university programs moving from expensive technologies such as film towards semi-professional digital video and new media. Training has drifted from technical and crew competencies to the filmmaker as writer, director, cinematographer and editor. This shift has resulted in the de-emphasis of the professional, industry-practice safety issues that once formed an integral part of film and television courses. The idea that you 'point and shoot' has made production paperwork and safety checklists almost redundant to the modern day student. However, screen production educators have a 'duty of care' to ensure that students are schooled in Occupational Risk Management (ORM) strategies. To date, the diversity and range of media education programs in Australia and the inclusion of ORM in their current curricula has remained largely un-documented. This study, initiated by ASPERA, sheds light on current practices in the Australian university environment. The investigation encourages new discourse amongst screen production educators towards an ORM Best Practices Model.

However, an investigation in the area of ORM is complicated by the intricate relationship between the university as an institution with its own system of ORM for student projects bound by legal and insurance responsibilities on the one hand, and the professional film industry, which navigates a differing set of legal and contractual obligations bound by trade union and industrial policy requirements on the other. Within this web of complexities, the screen production educator has a responsibility to undertake a 'duty of care' in regard to the student in his or her use of facilities and equipment both inside and outside the university. This paper argues that this 'duty of care' needs to be clearly understood and implemented through the curriculum. It argues that an ORM Best Practice Model should be considered which highlights requirements of general education in the area of screen production, the development of student self-assessment skills in ORM, and the implementation of ORM processes and systems.

\section{Background: OHS tertiary policies and Australian film and television regulations and practice}

In the Australian tertiary education system, Occupational Health and Safety (OHS) and risk assessment and implementation are directly related to the institution's OHS policies. These institutional policies comply directly with government-linked ORM legislation (Oughton 2010: 3). For example each University has to comply with their state based OHS legislation so NSW universities comply with the NSW Occupational Health and Safety Act, 2000. Most institutions have a 'one size fits all' ORM process 
that explains the administration and implementation procedure for tertiary staff and students. Other institutions may have a two-step ORM process in place, one for undergraduate projects and another for the post-graduate student. For example, at the University of Newcastle (UoN), the post-graduate student has to complete a research related Risk Assessment which is created for all areas of scientific research, and approval for the activity is managed through three levels which are dependant on the nature of the research activity and the level of identified risk, as assessed by the researchers. At UoN, the academic staff member identifies the risks involved in an undergraduate activity and lays out a risk mitigation process, which is approved by the UoN's Safety Review Committee. ${ }^{1}$

These institutional restrictions often impinge on the creative content of student productions, which would not happen in the screen production industry. For example, filming a piano on the beach, or a band performing at a traffic roundabout, or the use of props such as guns and knives are not allowed under standard university OHS guidelines. However, under industry guidelines, these same scenes are within the realm of possibility because managing risk is seen as an important process for ensuring that business and creative objectives are achieved. Details of current film and television industry practice can be accessed through a number of online sites OHS Management System for film and television industry employers (SPAA 2009), Occupational Health and Safety Management System (Film Victoria 2008). A CDROM titled 'OHS Risk Management for the film, television and commercial production industry' (SPAA 2008) has been tailored to film and television OHS industry practice is also commercially available. In the professional screen production environments, funds are available to commission safety reports, employ safety officers, stunt people, special effects teams, traffic controllers and theatrical armourers to undertake these sequences safely. While it is essential that professional productions facilities observe the correct film and television ORM protocols, it is deemed unrealistic to enforce the same level of ORM standards on tertiary filmmaking students.

This raises the conundrum between tertiary training and industry practice. Industry standards and practices play an important role in informing the learning environment, but ORM research on industry levels of compliance is meager. ${ }^{2}$ Regardless of the complexity of ORM protocols students must be able to recognize industrial ORM requirements for internships and future professional experience. The occupational health of screen production students has to be placed ahead of their creative endeavors. Furthermore while working on their own productions student need to be able to self-assess and mitigate risks within the guidelines and financial constraints of institutional policy. The role of screen production educators is to negotiate the institutional and industrial parameters within a tertiary environment. Academic educators, both in the design and teaching of screen production courses, must remain aware of their tripartite responsibility to provide a safe learning environment; educating students about professional filmmaking practices, responsibilities and regulations, without jeopardizing creative content. Research that investigates the role of screen production educators in delivering ORM is scares, but Nicholas Oughton's research reinforces the responsibility of screen production educators in meeting this 
goal. Following a detailed OHS study of 350 Queensland film and television employees, Oughton concluded that the dominant impression 'is of an industry that is inconsistent and variable in its application of OHS in management', and argues that one way to improve film and TV workers understanding of OHS is for 'teaching institutions to lead the way in improving OHS standards' (Oughton, 2005: 30-31). Another study conducted in 2005 provides a brief assessment of how the tertiary sector delivers ORM (Victorian Cultural and Recreation Industry Training Advisory Board 2006). A questionnaire, delivered to fifteen training providers and the ASPERA membership, and an assessment of three institutions' documentation, noted that the higher education sector tends to have a creative, rather than a craft focus when it comes to the education of ORM for film and television and that "[u]niversities do not teach from the national Film Television Radio and Multimedia Training Package" (Peoplearn 2005: 22). Given that there are no endorsed OHS Creative Arts guidelines for the tertiary sector (Oughton 2007; 2008), nor has there been a concise document endorsed at the national level by federal and state governments, unions, commercial filmmaking studios, public broadcasters and state funded film-making bodies. ${ }^{3}$ Consequently, screen production education providers are delivering ORM education in a largely ad-hoc fashion.

Over the last decade the ORM sector has implemented a standard way of assessing risk and controlling risk that is applied in all industries. The Risk Assessment Matrix is a robust method that steps the practitioner through a matrix that helps them identify the risks associated with daily activities. A Risk Assessment Matrix (see Appendix 1), is an ORM industry benchmark that can be used to identify and reduce risks, it also can be used to diminish the likelihood and consequences of a potential risk. While these matrices are useful tools in industry, they do require detailed explanation and understanding, for them to be used effectively in the classroom. Once the risk is selfassessed the practitioner is asked to eliminate the risk, or substitute the risk, isolate the risk or engineer a way to remove the risk. If the risk still remains after this process has been considered, then the use of personal protective equipment is needed or the employment of 'licensed' or 'ticketed' professionals are engaged for the safe completion of the activity. Due to its application to a wide range of industries, the Risk Assessment Matrix is a useful protocol for adoption in the education sector, and may play a crucial role in the development of student self-assessment skills in risk management.

A generic risk matrix is used by several screen production courses to help students mitigate risk through self-assessment. In a student production at UoN a student crew presented a script, which included a hostage siege that required a standard issue Glock police gun to be used as a prop. Although the students had access to the prop, this would not be allowed by the University's OHS policy, nor satisfy the film and TV industry's OHS guidelines (Screen Production Safety Review Committee 2004: 9294). The students were asked to explore how the risk could be mitigated. The first option was to employ a theatrically licensed armourer to supply a weapon and supervise the shoot, but this was financially not viable. The students considered 'elimination', to remove the gun from the script, and choose another dramatic device to elicit similar dramatic tension. The substitution of the gun for a baseball bat still 
required the employment of a safety officer or stunt double. Having exhausted all the 'substitution' options, the students began work on eliminating the gun from the script. The students revised the script, retaining the back-story, but re-writing the climax without using a weapon on set. Instead, the hostage was blindfolded and he presumed his captors had a weapon. This case study presents a way to manage risk elements by either elimination, or by reducing the level of risk from high to low or no risk, whereby it can be safely managed without employing professional safety officers at the institution's/student's expense. It is in the classroom environment that students need to be trained to assess the likelihood of a risk occurring, and the potential consequences of the risk, in developing life-long skills that may be implemented beyond the classroom/ in a professional environment.

While an industry practice/academic ORM model has been explained in OHS literature, it has not been implemented through policy to date (Oughton 2005; 29). Furthermore, with the absence of an ORM industry practice model that can be easily adapted to the educational environment, and an institutional framework specifically designed for scientific projects, screen production educators have had to appropriate existing systems and ORM matrices for their programs. Development of these ORM skill-sets for screen production may function as an appropriate educational tool, provide a grounding for industry experience and most importantly help educators to exercise a 'duty of care' when administering and teaching students about ORM practices. Certainly, the adoption of the risk management matrix in screen production programs signals that there is a wide range of effective ORM strategies employed in Australian tertiary institutions. In order to explore these viable educational tools, which tertiary institutions are undertaking to deliver film and television ORM curriculum, ASPERA set up an OHS sub-committee to conduct a study on tertiary institutions ORM curriculum that consolidates the various ORM methods adopted.

\section{Method}

This study uses a triangulated methodological approach combining an administered survey to 20 tertiary providers, and a case study from one of the leading academic institutions in screen production in Australia. The study was conducted by the ASPERA OHS sub-committee, which included representatives from Swinburne University of Technology, Griffith University and the University of Newcastle. The survey attempted to gauge the profile of degrees on offer, the ORM components of the curriculum and the incorporation of equipment and facility inductions. The case study tracks the recent review of the ORM processes at the Swinburne School of Film and Television.

\section{ASPERA film and television ORM survey analysis}

Approval was given by the ASPERA executive to administer the survey to its membership. The five-question survey was distributed via the ASPERA email list to 20 institutions, which conducted team-based production projects as part of the curriculum. ${ }^{4}$ A survey reminder was emailed out after the four-week turnaround due 
date to ensure a good response rate. Fourteen out of the twenty ASPERA member institutions responded to the OHS Risk Management Survey. Only a single respondent reported no process in place for assessing/teaching ORM for Screen Production. Thirteen respondents used a range of standard teaching techniques to convey Screen Production ORM information to the students. These respondents commonly reported that completion of the institutions paperwork and signed approval by the lecturer/tutor is mandatory before students may use equipment and facilities without academic supervision. Three respondents stated that the completed OHS and Risk Assessment forms ensured that the institutions public liability insurance covered students, actors and volunteers.

The data also evidenced a variation in the approach to educating students about Screen Production ORM, with one respondent conducting a discrete OHS Screen Production course; twelve respondents including the OHS instruction into coursework (five of these respondents assess the student's OHS and Risk Management forms); nine respondents providing additional Facility or Equipment OHS instruction; and four respondents requiring students to complete equipment competencies in addition to completing the OHS and Risk Management forms. The variations in approach are correlated with the type of degree program delivered by these institutions. Of the fourteen respondents, six offered Bachelor Degrees in Film and Television production; six respondents offered a Bachelor of Communication or Bachelor of Arts where a Major in Screen production is taught; while another respondent offers Foundational Diplomas, Graduate Certificates, Graduate Diplomas in filmmaking.

When investigating the curricula in more detail, only five institutions assessed the student's understanding of their ORM knowledge. This was done in various ways such as a Production Management unit delivered in first year; an ORM exam in an initial production unit; an online OHS test in first year of production; and an online assumed knowledge quiz for second and third year courses. Inductions and competencies were more widespread, with one respondent conducting an office induction, four delivering a compulsory lecture on ORM; and another four conducting equipment competencies in various forms. Two of the institutions who offer the Bachelor of Film and Television program offer specialized instruction, in the form of a week long 'Boot Camp' for their first year students, while the other provides level one first aid training and fire extinguisher induction training. Three respondents required equipment competencies modules to be undertaken for student to complete or pass first and second year courses. In addition to an equipment competency test, one institution restricts 'on-screen' action according to the year of instruction - for example, first year no guns, no children and no cars.

Eight respondents require Safety Reports to be completed by industry approved Film Safety Officers while six of these will have a Safety Officer on set when identified in a safety report. Two respondents ask students to self-assess their scripts against industry safety codes, and then to reduce identifiable risks to ensure a safe shoot. In risk assessments, these students are required to completely mitigate risk while complying with safety codes. This method also provides one way to manage institutions who are financially unable to provide industry-standard Safety Reports, 
and the on-set employment of safety officers, traffic controllers, armourers, or stunt men.

Eleven institutions supplied copies of the instruction sheets that explain the OHS and Risk management process that students need to complete to get approval for filming on and off campus unsupervised. Each institution had their own way of explaining the ORM issues and the paperwork demonstrated variations in content and length; a onepage health and safety summary of common risks on films sets; a 10-page instruction sheet on the risk management of student film and video productions; a 3-page filming safety guidelines and a 2-page lighting safety checklist; a dot-point film and TV rules and regulation protocols and safety report; a 2-page field trip procedural; and a single page production risk assessment worksheet. Another institution supplied incident reporting paperwork, which is directed to the institution's OHS committee.

A content analysis of the eleven ORM forms that students are asked to complete revealed three different approaches. In one category, detailed paperwork rigorously required students to complete on and off campus location survey forms and use of electricity on locations. These forms were dated in design and language. In the second category the ORM forms adopted a more updated approach to help the student assess the level of risk in their productions, by requiring students to complete a hazard identification checklist with reference to their scripts, filming techniques and locations. Five institutions, asked students to use a Risk Assessment Matrix to selfassess the likelihood and consequences of their filming risks, while the remaining group of five institutions only required students to self assess their projects against the - eliminate, substitute, isolate, engineer procedure that was explained through a Hazard Identification table. Finally of these eleven ORM forms, eight institutions asked students to assess 'off-screen' actions such as travel to and from location and manual handling.

\section{Case study: Swinburne School of Film and Television}

During 2009 and 2010, Swinburne School of Film and Television overhauled their OHS and Risk Management Program with the goal of delivering

a comprehensive Health and Safety program that adequately covers all the requirements of the program ... in regards to duty of care, and works in the best interest of the Film \& Television students in supporting and encouraging them to use best practice in all areas of Health and Safety in the production of their films (Holt 2010).

The OHS curriculum review was initiated by consulting with the institution's legal counsel to define the School's obligation to the students in regards to delivering ORM as an integral part of their screen production program. This consultation confirmed that University is not an employer and the students are not employees, as pertains to the ORM legislation in the state of Victoria. Therefore, the students are responsible for their own actions as taken on student productions. However, it is the responsibility of the University to take the highest 'duty of care' in regards to using the facilities and equipment, and to advise students of all the required procedures, information \& associated risks related to ORM. 
Peter Wassam, a specialist Film Industry OHS consultant, was engaged to consult on an educational program and to write an ORM checklist, resulting in the Swinburne Production Hazard Checklist and Risk Assessment document. ${ }^{5}$ Peter Wassam worked with Jill Holt, who led the review, and was assisted by Producer and Swinburne Film $\&$ Television sessional lecturer, Jane Ballantyne. As a result, the Swinburne Film and Television ORM Program was developed and is now delivered in three stages.

Firstly, a 3-hour ORM workshop is delivered early in semester one, which requires mandatory attendance for all incoming students into the Film and Television program. A panel of industry practitioners including a Producer, Safety Officer, Stunt Coordinator and a Traffic Officer from Victoria Police talk about their areas of specialization, and answer questions in regards to ORM. ${ }^{6}$ Secondly, the Production Management unit, which is delivered to all first year Film and Television students, provides a comprehensive overview of all aspects of ORM in the film industry and how to use the associated documents, specifically the Production Hazard Checklist and Risk Assessment form, and the Swinburne Production Manual. ${ }^{7}$

The third element that completes the students understanding of ORM is the implementation of the Production Hazard Checklist and Risk Assessment form. This document, which has been certified by Swinburne Legal, is available online via the Swinburne Film and Television website Clapperboard, alongside links to additional industry websites and documents, such as the SPAA online Management System (2009) and government legislation on working with children, animals, use of firearms etc.

The Production Hazard Checklist and Risk Assessment form is completed in two stages. The first stage occurs mid-way through the semester when draft scripts are reviewed by students and staff against the Risk Management Matrix and Hazard identification. By necessity, students must be involved in the initial stage of analyzing their scripts and are encouraged too 'write out' foreseeable risk items to meet the safety requirements. Final draft scripts are then submitted with a copy of the Production Hazard Checklist and Risk Assessment form, and are clearly identified as either no risk, self-managed risk, or risk requiring safety supervision. This is a legally binding document, signed and witnessed by the students and delivered to the appropriate lecturer to be assessed before production can begin. Once the students have signed off on their scripts and have been assessed on the appropriate risk rating, Swinburne's 'duty of care' as an educator has been satisfied.

This final stage of the process occurs once the scripts and ORM documentation have been reviewed. Swinburne staff will then follow up with those students who have identified either a self-managed risk or risk requiring safety supervision by making an appointment with a Safety Officer, who is employed by Swinburne to interview students on campus. The Safety Officer will advise the students how to eliminate/ manage the risk elements, or what measures to take to proceed with the risk, as identified. Should the student/s choose to proceed with the risk, it is then their responsibility to employ the appropriate safety personal to be 'green-lit' to go into production on their film. Although this may seem a considerable cost to the students, Holt has found that it is generally the graduate films that require safety officers and 
stunt coordinators on set and as these are group projects, the students share the costs. Should students fail to meet any of the hurdle requirements of the ORM program, they will not be given access to the Film \& Television equipment, and their projects will not be acknowledged for assessment purposes.

\section{Discussion}

The different ORM standards employed by each institution is relative to the scale of each screen production program. For example some Universities like Swinburne School of Film \& Television offer what appears to be professional style training courses, which deliver scaled down versions of industry ORM practice and process. While other universities, which offer screen production as less than one third of the degree program, offer the minimum levels of ORM education as they are educating media practitioners in a broader sense. In these general programs, time does not permit for the education of specific craft practices and film production approaches. Instead there may be an emphasis on multi-skilling and multi-tasking in production crew roles. Consequently, each teaching scenario presents its own challenges that the screen production educator must manage against film and television industry practice and a safe work environment for their students.

While the surveyed data exposes some variations in the depth of ORM instruction, it does confirm that all institutions require mandatory attendance for facility, equipment instruction or equipment competencies, and it confirms that access to equipment is denied until the facility, equipment induction or competency is completed. Just under half the respondents make elements of these educational sessions an assessable component of coursework. The survey also confirms that thirteen institutions will not permit students to undertake any filming activities without completing that institutions ORM paperwork and having it assessed by the appropriate staff member. These commonalities suggest a useful inclusion for a Best Practice Model.

An analysis of the survey results and the case study, suggests that a best practice model incorporate four teaching approaches, modeled on programs already offered by ASPERA member institutions:

- A two-step process that employs firstly a self-directed risk assessment of student productions incorporating both identification of risk and attempts to eliminate, substitute, isolate risk. Following this a final review of the risk assessment matrix should be employed to then identify the likelihood and consequences of the on-and off screen hazards occurring on set.

- Delivery of institutional ORM criteria in regards to University facilities and equipment

- Explanation of film and television industry ORM practices either embedded in coursework or as an addition to coursework for more specialized craft practices

- Tiered approach to film and video equipment and to 'on and off screen' action 
While the Swinburne case study explains a model that could be considered 'best practice', not all ASPERA institutions may be able to deliver this model due to their own program structures and financial limitations. However, the case study provides some important components that may be adapted to institutions, which offer a range of screen production courses.

\section{ORM best practice model for screen production}

In the first instance, institutions should look at a way of maintaining and enhancing the current delivery of equipment and facility inductions, and safety issues in regards to student productions. It is clear that students need to be made aware of the institutional requirements in relation to unsupervised productions.

Secondly, students must be provided with an understanding of industry standard procedures/operating methods, which they may encounter on the job. These sessions may be delivered as a component embedded within coursework or as an extension of the coursework. The continuation of mandatory attendance at these sessions is strongly recommended, while an assessment protocol that determines the students' level of understanding of the occupational health and safety issues related to the equipment, facilities and production of their films is also suggested.

Thirdly, the ORM documentation given to students needs to contain a self-directed risk assessment that uses a simple risk matrix engaging students in three important areas. Firstly having student's identify the risks in their scripted ideas, secondly, allowing students and staff a mechanism to review their safety plans in the light of any changes that may have been incurred during pre-production and finally suggest a revised action plan that documents how the student will manage and implement the risks they have identified. The Swinburne Production Hazard Checklist and Risk Assessment does incorporate these stages into the one form. However, it also needs to be recognized that in some instances the first stage of risk identification may occur in the classroom where students discuss ideas with academic staff. It is at this stage that elimination of risk can be best managed and implemented. Therefore, the institutions role in managing and mitigating risk is significant, and in some cases will actually remove much of the burden of risk assessment from the student. However, as a complement to this classroom learning it is strongly recommended that the ORM forms, that employ the self-directed dual-phase process is completed and signed off by the student/s. Additional planning paperwork may also be submitted with the ORM form, i.e. technical storyboards, also known as camera, lighting and blocking floorplans that illustrate the action, camera placement and lighting sources for that location. This bundle of documents then makes discussion of shooting plans and location variables more transparent from an approval point of view.

Finally, a tiered approach to 'on and off screen' activities is recommended. Enforcing restrictions with 'on-screen' actions is not a new pedagogical idea (Franklin 2001). However, it offers a practical methodology to the averting risk in student screen production. The table in Appendix 2 outlines a hierarchical approach towards the restriction of 'on and off screen actions' related to the students craft skill development 
and progressive self-assessment of ORM. The progressive release of equipment will allow students to become competent with basic visual storytelling techniques before progressing to more complicated filming scenarios. The first year restriction on electricity/lights only removes the hazardous handling of 240-volt power from first year shoots, while still allowing attention to natural lighting conditions aided by a foldable reflector. The introduction of 240-volt, filming lights and wolly dolly's can then be more effectively delivered to students in their second production subject or second year, depending on the structure of the course and amount of screen production courses on offer. Consequently, the introduction of more sophisticated camera equipment like jibs and full body steadicams can also be better managed through third year coursework when the student's have a reasonable understanding of filming techniques and shot construction.

\section{Conclusion}

In conclusion, the preliminary ORM Best Practice Model suggested in this paper attempts to build upon the foundations of already established screen production education in Australian universities. The model attempts to negotiate the boundaries of the institutional requirements of ORM which varies from program to program, while recognizing the importance of industry practices and protocols as functional guidelines and essential to the skill-set of graduates. Most importantly, the model emphasizes the need for students to be engaged in the risk assessment process through a dual-phase process. Students must recognize production feasibility and creative conception as inter-related and dynamic. Educators play a role in addressing creative adaptability in order to ensure safety on set. Also educators are preparing students to be consciously aware of ORM in any professional environment in which they may be engaged after graduation. The survey of ASPERA member institutions and the ORM case study of the Swinburne School of Film and Television curriculum review, demonstrates that tertiary institutions have responded well to the changes in the film and television industries approach to ORM over the last ten years. These Australian institutions are delivering a solid ORM education to screen practitioners that is not dissimilar to industry practice, and yet still delivers a duty of care in regards to safety first for staff and students engaged on production activities. The future goal is to uniform this educational approach to allow a ORM Best Practice Model to be implemented for Screen Production in the not too distant future.

\footnotetext{
Notes

${ }^{1}$ A practical example of a classroom to industry practice is the use of 240 -volt electricity required to power a basic redhead lighting kit. Incorrect handling of 240 -volt electricity could cause death via electrocution. The institution who issues the redhead lights administers much of the risk mitigation through the testing and tagging of the equipment to comply with the Australian/New Zealand 'Electrical safety practices-Film, video and television sites' AS/NSS 4249:1994. The screen production educator manages the OHS procedures through the induction of each student to use that equipment and by training students how to safely turn on these lights, change a light bulb, calculate wattages and safe procedures in putting lighting gels on the light's housing. The third step in this
} 
process is to develop student's skills towards analyzing potential risks in using the redhead lighting kit in a range of filming environments.

${ }^{2}$ Detailed workers compensation statistics for the Australian film and TV industry from 2001 show that sixty two incidents were documented through compensation claims (Oughton, 2005). The 'Screen Safety' report conducted by Film Victoria provided a snapshot of film and television professional's knowledge and skills in relation to OHS. This study found that apart from 'ticketed' film technician's e.g. traffic controller's, gaffers (electricians) and grips, that in regards to film and television OHS 'there is not a training culture apparent in the film and television sector and interviewees felt disenfranchised and disillusioned with the training they had been exposed to' (Victorian Cultural and Recreation Industry Training Advisory Board 2006: 47)

${ }^{3}$ A draft of the 'Occupational Risk Management in the Australian Film and Television Industry' was compiled by the Screen Production Safety Review committee (2004), unfortunately this document only ever existed in a draft form, and has now be removed from the MEAA website.

${ }^{4}$ The first survey question asked each institution to explain their program structure/requirements and film or screen production courses. The second and third questions determine if any film and television OHS Risk Management was taught as part of coursework and/or if facility and equipment inductions were offered on-top of coursework. If OHS was delivered through coursework respondents were asked to identify if it formed part of an assessable item. For facilities and equipment inductions respondents were asked to indicate if participation was mandatory and how those inductions were delivered and managed throughout a degree program spread across a number of years. The fourth question was a simple yes or no-'Does the OHS and Risk Management process permit students to film unsupervised both on and off-campus?' The final part of the survey required each institution to provide the OHS and Risk Management documentation given to students.

${ }^{5}$ Peter Wasson is the creator of the SPAA, Workcover NSW website.

${ }^{6}$ The film safety personnel have been extremely supportive in the delivery of the Swinburne ORM program, and generally offer student rates for their services. The Victoria Police Traffic Officers attend the O\&HS workshop free of charge. The O\&HS workshop is compulsory, in 2010, 276 students were enrolled with approximately $95 \%$ attendance recorded at the workshop. Students who missed the session or mid-year entry viewed a video link of the presentation and completed and returned a questionnaire to the Technical Manager before equipment could be borrowed.

7 This unit also gives students an overview of the Swinburne Production Manual, with an introduction to best industry practice and requirements in regards to the delivering the various pre-production and legal documents as required for their student film productions.

\section{Works cited}

Film Victoria, 2008 'Occupational Health and Safety Management system', Film Victoria, at http://ohs.film.vic.gov.au/ (accessed 1 March 2011)

Franklin, David 2001 'The professor as censor: Creative limitation and film production pedagogy' Journal of Film and Video 53 (1), 25-40

Holt, Jill 2010 Swinburne School of Film and Television OH\&S Risk Management Program. Melbourne, Swinburne University of Technology, unpublished correspondence

Oughton, Nicholas 2005 'Film and television production: A risky business' Journal of Occupational Health and Safety 21 (1), 23-31.

Oughton, Nicholas 2007 A Systematic Occupational Health and Safety Management Framework for Queensland's Film, Television and New Media Industry, Brisbane: Griffith University.

Oughton, Nicholas 2008 'A safety induction "Blue card" for the film, television and new media industry in Queensland and Australia' in Aspera 2008: Sharp Images/Blurred Boundaries, Melbourne: RMIT, at http://www.aspera.org.au/node/28 (accessed 18 October 2010) 
Oughton, Nicholas 2010 'Managing occupation risk in the arts and creative industries' Journal of Health, Safety and the Environment, 26 (3), 269-83

Oughton, Nicholas 2011 'Managing Occupations Risk in the Creative Industries: A New Perspectiveor has OHS Reached its used-by date?', in Broderick \& Leahy (eds) 'ASPERA: New Screens, new producers, new learning, TEXT Special Issue 11, April

Screen Production Safety Review Committee 2004 Occupational Risk Management in the Austalian Film and Telelvision Industry — Draft of National Safety Guidelines, Sydney: Screen Production Safety Review Committee, 144

Screen Producers Association Australia 2009 SPAA OHS Management System for film and television industry employers, at http://www.spaa.org.au/associations/8843/ohs/?page=218 (accessed 31 October 2010)

Screen Producers Association Australia 2008 OHS Risk Management-for the film, television and commercial production industry, at http://www.spaa.org.au/associations/8843/ohs/?page=435 (accessed 1 March 2011)

Victorian Cultural and Recreation Industry Training Advisory Board 2006 Screen safety: a national training approach, Melbourne: Peoplelearn, 3

\section{Appendix 1}

\section{Risk Assessment Matrix}

\begin{tabular}{|c|c|c|c|c|c|}
\hline \multirow{2}{*}{ Likelihood } & \multicolumn{5}{|c|}{ Consequences } \\
\cline { 2 - 6 } & Insignificant & M inor & Moderate & Major & Severe \\
\hline \multirow{2}{*}{ Almost certain } & M & H & H & E \\
\hline Likely & M & M & H & H & E \\
\hline Possible & L & M & M & H & H \\
\hline Unlikely & L & M & M & M & H \\
\hline
\end{tabular}

\section{Appendix 2}

\section{Tiered approach to 'on and off screen' activities}

\begin{tabular}{|l|l|}
\hline Year & Restriction \\
\hline $1^{\text {st }}$ year undergraduate or first production subject. & $\begin{array}{l}\text { No weapons, No vehicles, No children, No } \\
\text { lights/electricity, No stunts, No SPFX, No wolly } \\
\text { dolly, No cranes, jibs or steadi-cams }\end{array}$ \\
\hline $\begin{array}{l}2^{\text {nd }} \text { year undergraduate or second production } \\
\text { subject }\end{array}$ & $\begin{array}{l}\text { No weapons, No stunts, No SPFX, No cranes, or } \\
\text { steadi-cams }\end{array}$ \\
\hline $3^{\text {rd }}$ year undergraduate & $\begin{array}{l}\text { Use of jibs or cranes \& steadi-cam with training, } \\
\text { Weapons student pay for Theatrical Armourer, } \\
\text { Stunts with Safety Officer instruction }\end{array}$ \\
\hline Post Graduate & Industry Standards apply \\
\hline
\end{tabular}

